\title{
The stability of preferences - a social-cognition view
}

\section{Tilmann Betsch*}

Department of Psychology, University of Erfurt, Erfurt, Germany

*Correspondence: tilmann.betsch@uni-erfurt.de

Attitudes guide behavior. The socialcognitive approach to decision-making has been building on this assumption for almost a century (Allport, 1935). In this field, the model of reasoned action (Fishbein and Ajzen, 1974) was probably the most influential advance in describing the relation between attitudes and behavior. Accordingly, attitudes are the key predictor of behavioral intentions. They are formally described as a function of a linear integration of evaluations and probabilities (beliefs). The attitudinal part of the model dovetails with the subjectively expected-utility (SEU) approach to risky decision-making (Edwards, 1954). In line with attitude-behavior models, preferences are stable attitudes toward behaviors.

After its formation, an attitude can be stored in memory in association with the attitude object (e.g., Fazio, 1990; Wilson et al., 2000; Betsch, 2005). Attitude storage opens the path to stability. If a person re-encounters an attitude object, she can look up her attitude in memory and use it for subsequent judgment and choice. Individual preferences should be stable to the extent that the person relies on stored attitudes.

This so-called "file-drawer" notion (Wilson and Hodges, 1992), however, has been challenged by empirical evidence. Attitudinal responses in risky and nonrisky choice domains were shown to be susceptible to a variety of task conditions. Krosnick and Schuman (1988) showed that response order, question wording and format systematically affect attitude judgments irrespective of their subjective importance, extremity, and certainty. In a similar vein, empirical violations of the axioms of decision theory challenged the notion that preferences are stable (e.g., framing effect, Tversky and Kahneman, 1981).

The temporary construal approach, in its extreme version, assumes that individuals always construct attitudes on the spot (Schwarz, 2000). In this view, stability is a function of the situation. In stable situations the sample of information (salient stimuli, activated knowledge) is invariant. Consequently, attitudinal judgments and behaviors are expected to be stable. If the situation changes, however, the sample of information changes as well and so will attitudes and behaviors. Accordingly, attitudes are transient constructions. Therefore, preferences cannot be stable.

The focus on variability, however, is prone to yield an un-representative picture of human behavior. Numerous examples of behavioral rigidity can be cited, both from everyday observation and controlled studies. Individuals regularly obey norms, repeat their routines, and fancy the same things two days in a row. Correspondingly, there is a bulk of psychological research demonstrating stability, especially in the field of learning. In their famous demonstrations of the Einstellung-Effect, Luchins and Luchins (1959) showed that only a few implementations of a problem-solving strategy suffice to induce a tendency to maintain the strategy even when less costly strategies are adequate. In recurrent risky choices, prior experience fosters maintenance of behavioral options (Betsch et al., 2001) and decision strategies (Bröder and Schiffer, 2006), even following changes in the pay-off structure that render the routine a maladaptive choice. A few behavior repetitions (less than 10) suffice to induce counter-intentional relapse errors ${ }^{1}$ in subsequent choice (Betsch et al., 2004). In research on attitude-behavior models, Bentler and Speckart (1979), for instance, suggested including past behavior as an additional predictor in the Fishbein-Ajzen model.

How is it possible that there is evidence for both variability and stability in behavior? Many studies on variability employ tasks and judgment domains in which individuals lack behavioral experience. In contrast, studies on stability often assess

${ }^{1}$ A relapse error occurs if the actor performs a routine behavior against his or her intention to deviate from this routine. behavior in recurrent tasks. It is widely acknowledged, however, that experience matters. Decisions based on experience yield different results from those in oneshot situations (e.g., Hertwig et al., 2004). Thus, one might conclude that preferences should be labile in new situations and stabilize with behavioral experience.

Note, however, that the behavioral invariance observed in recurrent and experienced-based situations is not a sufficient condition for inferring preference stability. According to attitude theory, preferential stability requires that the attitude remains stable and guides choice. Repetitive experience, however, could merely result in increasing the association between a stimulus and a response. If this were the case, we would expect stability in recurrent situations and variability when situations change in the sense that the learned stimulus is no longer present. Explaining stability in stable situations does not necessitate the assumption of a stable attitude because it is the stimulus situation and not the attitude that might induce stable responses. Stimulus-directed choice is likely to occur if a behavior has been repeated so frequently in the past that it has been "frozen into habit” (James, 1890/1950; Verplanken and Aarts, 1999). Habits are responses that are instantiated automatically upon recognizing the associated stimulus. Indeed, there is evidence that highly frequent behavior repetition can outperform attitudes and intentions (Ouellette and Wood, 1998). On the other hand, the fact that habits are implemented in a stimulus-directed fashion without involving goals and intentions (Wood and Neal, 2007) does not speak against the possibility that attitudes can also become stable with behavior repetition and may systematically guide intentional decisions.

Two conditions must be met to justify the assumption that repetition paves the way to preference stability. First, previous behavior must increase the association between an attitude and an object. Accordingly, response latencies for attitude judgments 
were found to decrease with increasing frequency of prior activation of the attitude object (Fazio et al., 1986). Most important, studies using a conceptual priming technique show that activation of an attitude object can result in automatic activation of attitudes (Fazio et al., 1986).

Second, if it is truly the attitude that can guide behavior in intentional decisions, than we should observe a generalization of the preferred behavior to conditions that deviate from those under which the behavior has been learned. Generalization should occur especially for frequent compared to infrequent behaviors because in the former the behavior-attitude association is strong. Such transfer effects could not easily be accounted for by a stimulus-response model.

The following demonstration provides evidence of a generalization of strong attitudes. Sixty undergraduates from various majors at the University of Erfurt received vignettes involving food choices in everyday settings. Half of the behaviors were frequently performed in the past, such as drinking coffee or tea at breakfast. Others were infrequent such as foreign meals offered on the exchange-students day. Measures of attitudes toward the alternatives (nine-point rating scale: dislike-like) and choices were assessed twice with a 2 -week delay in between. At the second assessment, participants were randomly assigned to two conditions. Half of the participants received descriptions of new situations mostly atypical of everyday settings. The other half received the same descriptions that they were exposed to at the first assessment. Even though the situations differed between the two conditions, the set of alternatives was identical.

Mean correlations $(r)$ between attitudes and choices over vignettes were generally above 0.50 and significant - both within and between the two times of measurement. First-time attitudes and choices were equally strongly associated with secondtime choices. These results indicate that attitude-choice relations were quite strong and stable over time. More revealing, however, are the results from a comparison of old and new situations. For frequent behaviors, the correlations between the first-time attitudes and choices and second-time choices were substantially larger in new (mean $r=0.90$ ) as compared to old situations (mean $r=0.66)$. For infrequent behaviors, a reverse pattern for old $(r=0.70)$ and new situations $(r=0.59)$ was obtained.

Not only the predictive power of past choices but also the predictive power of attitudes seems to stabilize with behavior repetition over time and situations. Generalization indicates that behavior repetition appears to stabilize preferences beyond creating mere stimulus-response associations. Hence, one might conclude that stability in preferences is a function of behavioral repetition and storage processes.

Attitude research, however, suggests that consolidation of attitude-behavior relations in memory is not a sufficient condition for stability because the cognitive processes at the time of decision matter as well. Individuals can use different styles of thinking involving more or less deliberative effort (Evans, 2008). Economists often assume that individuals must think carefully to arrive at good (rational) decisions (Hertwig and Ortmann, 2001, for a discussion). Thus, violations of the axioms of rationality (e.g., preference reversals) may be attributed to shallow thinking under flawed incentive structures.

Does thorough thinking foster stability? When considering theorizing and empirical results from attitude research, one arrives at the opposite prediction. In his MODE-model, Fazio (1990) assumes that reliance on stored attitudes increases the less a person is motivated and able to think carefully about the decision. Under high motivation and in the absence of constraints, the individual is expected to engage in a new assessment of risks and benefits. In line with this prediction, individuals have been found to change preferences when "thinking too much" (Wilson and Schooler, 1991). Accordingly, individuals should be more likely to rely on prior attitudes if they make decisions without investing much cognitive effort (Betsch and Glöckner, 2010).

From the social-cognition approach, we can conclude that preferences (attitudes) can indeed stabilize and yield stability in judgment and decision-making under certain conditions. Stability is probably a joint function of memory and judgment processes. We should expect stability to increase with behavior repetition in the past and when individuals do not think much before making their decisions.

\section{REFERENCES}

Allport, G. W. (1935). "Attitudes" in Handbook of Social Psychology, ed. C. Murchison (Worcester, MA: Clark University Press), 798-844.

Bentler, P.M., and Speckart, G. (1979). Models of attitudebehavior relations. Psychol. Rev. 86, 452-464.

Betsch, T. (2005). "Preference theory - an affect-based approach to recurrent decision making" in The Routines of Decision Making, eds T. Betsch and S. Haberstroh (Mahwah, NJ: Lawrence Erlbaum), 39-65.

Betsch, T., and Glöckner,A. (2010). Intuition in judgment and decision making: extensive thinking without effort. Psychol. Inq. 21, 1-16.

Betsch, T., Haberstroh, S., Glöckner, A., Haar, T., and Fiedler, K. (2001). The effects of routine strength on information acquisition and adaptation in recurrent decision making. Organ. Behav. Hum. Dec. 84, 23-53.

Betsch, T., Haberstroh, S., Molter, B., and Glöckner, A. (2004). Oops, I did it again - relapse errors in routinized decision making. Organ. Behav. Hum. Dec. 93, 62-74.

Bröder, A., and Schiffer, S. (2006). Adaptive flexibility and maladaptive routines in selecting fast and frugal decision strategies. J. Exp. Psychol. Learn. Mem. Cogn. 32, 904-918.

Edwards, W. (1954). The theory of decision making. Psychol. Bull. 51, 380-417.

Evans, J. S. B. T. (2008). Dual-processing accounts of reasoning, judgment, and social cognition. Annu. Rev. Psychol. 59, 255-278.

Fazio, R.H. (1990). Multiple processes by which attitudes guide behavior: the MODE model as an integrative framework. Adv. Exp. Soc. Psychol. 23, 75-109.

Fazio, R. H., Sanbonmatsu, D. M., Powell, M. C., and Kardes, F. R. (1986). On the automatic activation of attitudes. J. Pers. Soc. Psychol. 50, 229-238.

Fishbein, M., and Ajzen, I. (1974). Attitudes towards objects as predictors of single and multiple behavioral criteria. Psychol. Rev. 81, 59-74.

Hertwig, R., Barron, G., Weber, E. U., and Erev, I. (2004). Decisions from experience and the effects of rare events in risky choice. Psychol. Sci.15, 534-539.

Hertwig, R., and Ortmann,A. (2001). Experimental practices in economics: a methodological challenge for psychologists. Behav. Brain Sci. 24, 383-451.

James, W. (1890/1950). The Principles of Psychology, Vol. 1. New York: Dover.

Krosnick, J. A., and Schuman, H. (1988). Attitude intensity, importance, and certainty and susceptibility to response effects. J. Pers. Soc. Psychol. 54, 940-952.

Luchins, A. S., and Luchins, E. H. (1959). Rigidity of Behavior. A Variational Approach to the Effect of Einstellung. Eugene: University of Oregon Press.

Ouellette, J. A., and Wood, W. (1998). Habit and intention in everyday life: the multiple processes by which past behavior predicts future behavior. Psychol. Bull. 124, 54-74.

Schwarz, N. (2000). AGENDA 2000 - Social judgment and attitudes: warmer, more social, and less conscious. Eur. J. Soc. Psychol. 30, 149-176.

Tversky, A., and Kahneman, D. (1981). The framing of decisions and the psychology of choice. Science 211 , 453-458.

Verplanken, B., and Aarts, H. (1999). Habit, attitude, and planned behavior: is habit an empty construct or an interesting case of goal-directed automaticity? Eur. Rev. Soc. Psychol. 10, 101-134.

Wilson, T. D., and Hodges, S. D. (1992). “Attitudes as temporary constructions" in The Construction of Social 
Judgment, eds L. L. Martin and A. Tesser (Hillsdale, NJ: Erlbaum), 37-65.

Wilson, T. D., Lindsey, S., and Schooler, J. W. (2000). A model of dual attitudes. Psychol. Rev. 107, 101-126.

Wilson, T. D., and Schooler, J. W. (1991). Thinking too much: introspection can reduce the quality of preferences and decisions. J. Pers. Soc. Psychol. 60, 181-192.
Wood, W., and Neal, D. T. (2007). A new look at habits and the habit-goal interface. Psychol. Rev. 14, 843-863.

Received: 28 June 2011; accepted: 11 October 2011; published online: 15 November 2011.

Citation: Betsch T (2011) The stability of preferences - a social-cognition view. Front. Psychology 2:290. doi: 10.3389/ fpsyg.2011.00290
This article was submitted to Frontiers in Cognition, a specialty of Frontiers in Psychology.

Copyright $\odot 2011$ Betsch. This is an open-access article subject to a non-exclusive license between the authors and Frontiers Media SA, which permits use, distribution and reproduction in other forums, provided the original authors and source are credited and other Frontiers conditions are complied with. 